
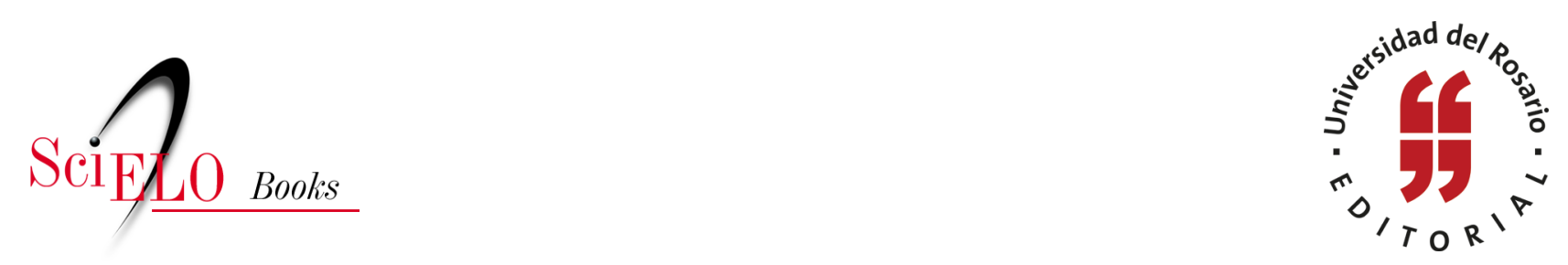

\title{
Capítulo II \\ El trabajo en Pueblo Viejo: conservación ambiental y oportunidades laborales
}

\author{
Felipe Rojas Arias
}

\section{SciELO Books / SciELO Livros / SciELO Libros}

ROJAS ARIAS, F. El trabajo en Pueblo Viejo: conservación ambiental y oportunidades laborales. In: Ayer mineros, hoy ecoguías y concesionarios: tensiones en torno a la conservación ambiental, el uso de la tierra y el trabajo en Guasca, Cundinamarca [online]. Bogotá: Editorial Universidad del Rosario, 2015, pp. 75-129. Opera prima collection. ISBN: 978-958-738-589-2.

https://doi.org/10.7476/9789587385892.0003.

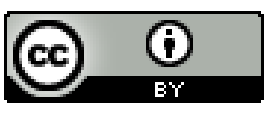

All the contents of this work, except where otherwise noted, is licensed under a Creative Commons Attribution 4.0 International license.

Todo o conteúdo deste trabalho, exceto quando houver ressalva, é publicado sob a licença Creative Commons Atribição 4.0.

Todo el contenido de esta obra, excepto donde se indique lo contrario, está bajo licencia de la licencia $\underline{\text { Creative }}$ Commons Reconocimento 4.0 . 


\section{Capítulo II \\ El trabajo en Pueblo Viejo: conservación ambiental y oportunidades laborales}

$\mathrm{Al}$ iniciar este trabajo y conocer a los vecinos del sector, aún no se había definido con claridad el problema de investigación. Pronto, a partir de las conversaciones con los habitantes del sector de Pueblo Viejo, se identificó que uno de los principales cambios que había sufrido la localidad, desde la época de la mina, había sido con respecto a la oferta de trabajo. Esta trasformación no solo tiene que ver con el cierre de la mina, sino con la constitución de la RBE en el año 2007. De allí se derivó parte del interés por indagar sobre las problemáticas de la constitución de áreas de conservación ambiental para los pobladores locales, en particular, las tensiones a nivel laboral.

En la primera parte de este capítulo se analizarán las razones de la añoranza de los pobladores locales por la época en que operaba la mina a nivel laboral y se caracterizará parte de la situación actual de trabajo en el sector. Posteriormente, en la segunda sección de este apartado, se analizarán las tensiones en torno a la situación de trabajo con respecto a la RBE. 


\section{El trabajo en el sector hoy en día: dificultades y añoranzas}

-Vecina: Pues cuando la mina sí había trabajo, sí eso llegaban de bastantes partes, de Gachalá, de Junín venían gente a trabajar. Y como el doctor Hermann tenía hato, entonces los unos a los hatos y los otros a las minas, y así. Pero ahí vivía la gente y ahí se defendía con el sueldito que ganaba. -Felipe Rojas: Y ahora la situación de trabajo o sea de la cantidad de trabajo que hay acá...

-Vecina: Pues únicamente... [hay] poco trabajo. Ahora sí es poco trabajo porque la mina abastecía a bastantes obreros sí, eso sí y la agricultura también. Ahora sí poco trabajo hay por aquí. Poco trabajo porque como la mina la privatizaron y todo eso, entonces ya murió el doctor Hermann y entonces ya eso se acabó. Sí, señor. Pero sí eso sí abastecía, abastecía bastantes obreros, claro. Eso ya le digo por allá venían de Gachalá, de Junín, venían a trabajar aquí, a la mina. (Entrevista a vecina de Pueblo Viejo, 2 de septiembre de 2012)

La época en que funcionó la mina de piedra caliza es recordada por los habitantes de Pueblo Viejo como un periodo en donde existía una gran cantidad de puestos de trabajo. Si bien los vecinos expresan reparos sobre la mina a nivel ambiental por el daño a fuentes hídricas o la erosión de algunos terrenos, e incluso sobre lo pesado que resultaba el trabajo allí y las afectaciones que traía a la salud de los obreros, en particular en los pulmones por cuenta del polvo 
de la cal, algunos rememoran esos tiempos como un periodo de bonanza en la zona en cuanto a la situación laboral, pues había cantidad y calidad (en cuanto a prestaciones sociales) en el trabajo. Los obreros de la compañía explotadora de cal, empresa que operó la mina por más de sesenta años, contaban con un contrato laboral y prestaciones sociales, y muchos de sus trabajadores lograron pensionarse. Por otro lado, la situación actual de trabajo de Pueblo Viejo no es muy prometedora.

El cierre de la mina en 1992 condujo a esta zona a un declive a nivel laboral que se extiende a la actualidad. Acorde con algunas de las opiniones locales, uno de los principales problemas laborales no consiste propiamente en el desempleo, sino en la falta de ofertas laborales en Pueblo Viejo que permitan a las personas trabajar sin la necesidad de desplazarse por fuera de la vereda. En consecuencia, la necesidad de salir a buscar empleo por fuera de Pueblo Viejo, en buena medida por el vacío que dejó la mina, se constituye en una de las dificultades a nivel laboral que identifican los habitantes locales:

No, aquí no se consigue trabajo. Para trabajar toca salir a trabajar por allá a los pueblos, a la ciudad, [...]. (Entrevista a vecina del sector, 8 de septiembre de 2012).

$[\ldots]$.

Hay mucho desempleo en hombres y mujeres. Mire, por decir algo, esas señoritas, esas señoras acá no tienen empleo. Están consiguiendo trabajo por otros lados, tienen que irse hasta la ciudad, consiguen el empleo, pero entonces salen 
muy tarde en la noche y no pueden regresar a la casa [...]. (Entrevista a vecino del sector, 3 de septiembre de 2012)

La investigación en campo sobre la situación de trabajo en la vereda arrojó los siguientes datos (figura 4).

Figura 4. Tipos de trabajo remunerados en Pueblo Viejo

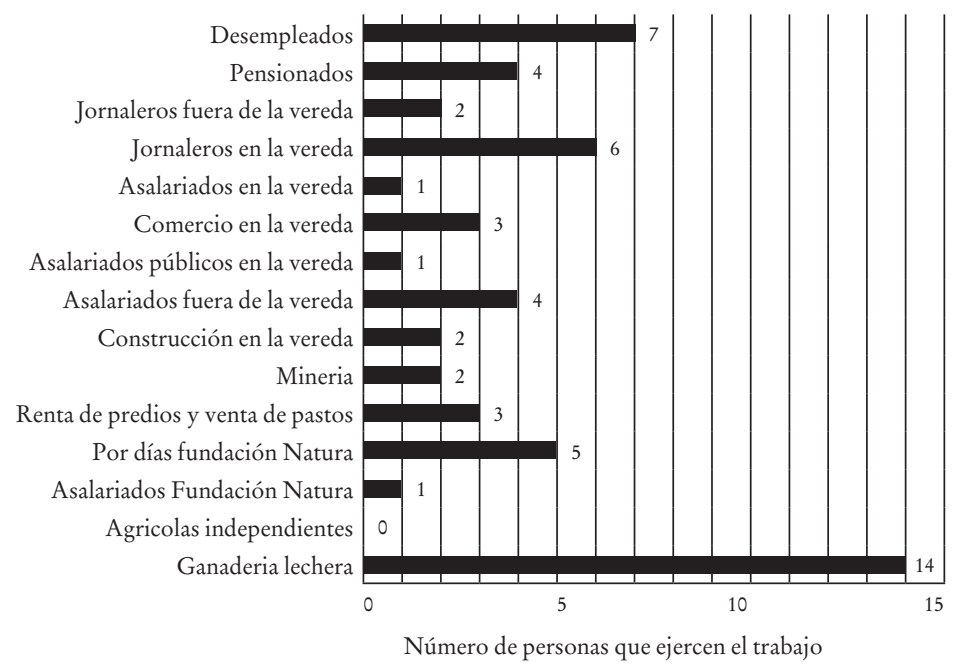

Fuente: elaboración propia.

Estos datos, recolectados por medio de las entrevistas y el trabajo de campo, podrían indicar que la situación laboral de la vereda no es precaria. ${ }^{8}$ Sin embargo, no se trata de una apreciación errada por parte de los pobladores de Pueblo Viejo el sostener que actualmente la situación laboral de

8 Con situación laboral precaria se hace referencia a la falta de ofertas de trabajo, inestabilidad laboral, falta de contratos y deficiencia en la remuneración y las prestaciones. 
la vereda es precaria, más bien refleja la añoranza de unas condiciones laborales pasadas muy favorables en cuanto a "calidad" (prestaciones sociales, contratos laborales, dotaciones, sueldos fijos, entre otros) y cantidad de los empleos, actualmente ausentes en la vereda.

Los vecinos del sector añoran, en cuanto a calidad y cantidad de puestos de trabajo, los últimos veinte años de la mina en donde el sindicato de trabajadores generó el otorgamiento de prestaciones, mejoras en el salario y dotaciones, lo que llevó a que las condiciones laborales de los obreros mejoraran considerablemente. Si bien pareciera que en la relación entre población laboralmente activa y número de trabajos no existe un desfase actualmente en Pueblo Viejo, a nivel de la calidad del empleo, que se define para este caso como estabilidad, contrato laboral y prestaciones sociales, sí hubo una desmejora a partir del cierre de la mina. En ese entonces los trabajadores de la compañía explotadora de cal, calculados a partir de las memorias orales en más de treinta trabajadores, contaban con dotaciones, prestaciones sociales y contrato laboral.

En este sector trabaja una población total de 37 personas. La figura 1 supera este número, pues la discriminación corresponde al tipo de labores, muchas de las cuales son realizadas simultáneamente por una misma persona. Por ejemplo, un jornalero en el sector trabaja en fincas haciendo distintas labores, pero a su vez se dedica a pastorear su propio ganado y vender la leche que este produce. De estas 37 personas que trabajan, 6 se desempeñan por fuera de Pueblo Viejo. Esto sugeriría que no existe ausencia de ofertas laborales en el 
sector, pues solo el $16,2 \%$ de los habitantes locales que trabajan deben buscar empleo por fuera, cifra que a su vez representa el porcentaje de déficit de oferta laboral en la vereda. Sin embargo, la cifra no es desdeñable, en especial si se considera que estos datos tienen como base la población que actualmente reside en el lugar y no la que tuvo que migrar a vivir a otras zonas en busca de empleo.

Este proceso de disminución de la oferta de puestos de trabajo que tuvo lugar en Guasca no solo tiene que ver con el declive de la mina, pues a nivel más general, se relaciona con una precarización de las condiciones laborales del campo, cuya base no es únicamente la expansión de la industria y los servicios y el crecimiento urbano. El proceso expansivo económico que supuso la mina generó un amplio número de fuentes de trabajo y mejora de calidad de vida, mientras que una actividad conservacionista, anclada en procesos de ecoturismo y servicios ambientales, fue una de las causantes de disminución del trabajo local. Sin embargo, la precarización a la que se hará referencia más adelante, en cuanto al trabajo en las grandes fincas aledañas, está relacionada también con los procesos de industrialización y modernización que afectaron la oferta de puestos de trabajo estables y con buenas condiciones en las áreas rurales, y que convirtieron al campo en uno de los sectores con mayor informalidad laboral (Cavalcanti y da Mota, 2003).

Durante el trabajo de campo, se pudo constatar que muchas personas que no viven actualmente en Pueblo Viejo tuvieron que salir de allí en el momento que alcanzaron la edad laboral, debido a la falta de ofertas de empleo. 
Una tendencia en el sector consiste en la salida de los miembros más jóvenes del hogar una vez finalizan sus estudios secundarios. Sus padres se quedan en el lugar, pero los hijos, algunas veces por tener otro tipo de proyectos de vida que no involucran el trabajo en el campo, y en otros casos debido a la falta de empleos, emigran:

-Felipe Rojas: ¿Y por qué por acá no trabajaron [sus hijas]? -Vecina: No, por aquí no había trabajo... Tocaba salir era allá, ir a Bogotá a trabajar. Mi hija, la mayor, ella sí se fue a trabajar, salió de estudio, ella sí hizo todo su bachiller y salió de estudio y ahí sí se fue a trabajar.

-F: ¿Y en qué trabajaron sus hijas?

-V: Trabajaban en casa de familia (refiriéndose a labores vinculadas al servicio doméstico).

-F: ¿En dónde?

-V: Estuvieron trabajando en La Calera. La Natalia9 estuvo trabajando en La Calera, en una casa de familia. La otra también. Todas mejor dicho trabajan en casa de familia... en La Calera y en Bogotá. Y una que estuvo trabajando también fue en Sopó por allá para el lado de Alpina que estuvo trabajando con un primo que estaba trabajando. (Entrevista a habitante del sector, 8 de septiembre de 2012)

Nombre cambiado. 
En otra entrevista un vecino comentaba:

Felipe Rojas: ¿Pero actualmente acá las fuentes de empleo, digamos que sí alcanzan a dar abasto para la población o hay gente que le $[\ldots]$ ?

-Vecino: No, de acá se tienen que [ir]. Mucha gente está trabajando por allá en las empresas, en Alpina, en cartones, en las floristerías abajo. Sí, porque a este lado no... ya ocupan en una finca dos, tres personas nada más. (Entrevista a vecino del sector, 20 de agosto de 2012)

Estos fragmentos de entrevista ejemplifican la situación de muchas de las personas que tuvieron que salir del sector por falta de oportunidades laborales. Los mayores se quedaron para no dejar sus propiedades o simplemente porque no sentían que a sus edades encontrarían oportunidades o se adaptarían a modos de vida en el área urbana. De tal suerte que muchos de sus hijos salieron en busca de opciones laborales y educativas acordes con sus proyectos personales de vida, o por causa del déficit laboral, no solo en cuanto a cantidad de trabajo, sino a su calidad.

Parte de la situación laboral adversa se constató, además, en conversaciones con una habitante del sector, quien hacía referencia a las dificultades que afrontaban los trabajadores de dos fincas lecheras de gran extensión del lugar, conocidas en el sector como hatos. Según esta persona, estas fincas no brindan estabilidad laboral a sus trabajadores, pues los despedían constantemente. Esas fincas corresponden a grandes extensiones de tierra con vocación ganadera y agrícola que 
no están supliendo las necesidades laborales del sector; es más, han precarizado el trabajo al pagar bajos salarios y no brindar estabilidad a sus trabajadores.

Esto se relaciona, en una escala más amplia, con las crisis laborales y económicas del sector rural, así como el crecimiento industrial urbano que generaron flujos de migración rural-urbana o rural-rural (Cavalcanti y da Mota, 2003; Flores y de Grammont, 2003). La creciente urbanización en conjuntos cerrados exclusivos que ha tenido el municipio de Guasca y sus alrededores (La Calera y Sopó) ha generado fuentes de empleo en condominios y clubes campestres ubicados en la zona en el servicio doméstico, jardinería, entre otros. Esto ha tenido repercusiones en la migración de personas de las veredas hacia las cabeceras municipales o la tendencia a buscar trabajo fuera de las zonas rurales o las actividades agropecuarias. Teniendo en cuenta la crisis productiva del sector rural, la urbanización ha permitido la oferta de puestos de trabajo en empleos como construcción, servicio doméstico, jardinería, asistencia en deportes, cuidado de niños y mascotas, entre otros.

Se pudo constatar en campo parte de las dificultades laborales rurales en Pueblo Viejo durante el desarrollo de un trabajo con los niños de la IEDc, sede Rodríguez Sierra, ubicada en Pueblo Viejo, junto con la pedagoga Ana María Ramos. En una de las visitas a la escuela, uno de los niños comentó que se iba de la vereda y, ante la pregunta del por qué, dijo que a su mamá la habían "emproblemado” en la finca, acusada de un robo. Agregó: "Felipe, es que a nosotros de todas partes nos sacan”. Este tipo de comentarios y las visitas 
a la escuela permitieron apreciar la situación de migración y falta de estabilidad laboral de las familias. En la escuela, el número de alumnos fluctuaba con constancia. Los hijos de aquellos que trabajaban en las dos grandes fincas de Pueblo Viejo llegaban a mediados del año escolar a la escuela y antes de que este finalizara, sus padres o acudientes eran despedidos por sus patrones, u "obligados" a renunciar acusados de administrar inadecuadamente las fincas o efectuar robos. Varios niños llegaban y salían de la escuela porque sus padres debían emigrar del sector y buscar trabajo en otro lugar.

Toda esta situación refleja unas dificultades laborales que no solo corresponden a Pueblo Viejo, sino que también se presentan en otros escenarios rurales. Las familias que llegaban de lugares como Muzo (Boyacá), Bojacá y El Rosal (Cundinamarca), entre otros, y posteriormente emigraban, hacen parte de una dinámica en que las personas pasan de finca en finca, de un trabajo a otro. La modalidad de trabajo consiste en que el dueño de la tierra los deja vivir en el predio y les paga un sueldo y, como contraparte, ellos deben administrar su finca, lo cual consiste en cuidarla, ver por los animales y rendir cuentas al dueño por la venta de los productos del hato. Se puede decir que es una modalidad de concierto, a saber, una forma de trabajo en la que un "labrador sin tierra [se encuentra] vinculado a una hacienda" (Fals Borda, 1961, p. 320). En este caso, y según el lenguaje local, es una labor en la que un trabajador vinculado a una finca trabaja las tierras de su dueño y del ganado, a cambio de un sueldo y una vivienda. Es una modalidad de migración rural-rural en la que las familias emigran como núcleo; muchas de ellas dejan 
sus lugares de origen y sus propias tierras debido a las crisis económicas que las obligan a proletarizarse en otros lugares. Estas familias basan su economía migrante en la capacidad de venta y cantidad de mano de obra que puedan ofrecer (Flores y de Grammont, 2003). Estos autores definen este tipo de migración como circular, es decir, un cambio de residencia constante sin regreso inmediato al lugar de origen, sino hacia otro frente de trabajo.

Adicional a esta inestabilidad laboral, los planes de desarrollo municipal no han sido suficientemente eficaces en combatir el desempleo rural por falta de subsidios, asistencia técnica al productor, acceso a la tierra, entre otros. Parte de la problemática de la situación de Pueblo Viejo tiene que ver con el actual Plan de Desarrollo de Guasca que entiende que el desarrollo es corresponsabilidad entre las instituciones y la comunidad:

El Plan de Desarrollo 2012-2015 construye sus objetivos estratégicos, sus programas, proyectos y subproyectos bajo una concepción multidimensional del desarrollo, lo cual implica trascender la actuación sectorial del estado y proponer nuevos modelos de gestión y de relacionamiento con la ciudadanía corresponsable de su propio desarrollo. (Municipio de Guasca, 2012, pp. 26-27. Cursivas del autor)

El Plan de Desarrollo Municipal de Guasca habla de medidas frente a la asistencia técnica al productor, al presentar un modelo ideal para "la alta productividad y competitividad en el desarrollo económico” (2012, p. 141). No obstante, 
este modelo no se aplica para el caso de los pobladores de la vereda, como se pudo apreciar durante el desarrollo del trabajo de campo.

Los pequeños ganaderos locales que trabajaban de forma independiente, hasta donde se apreció en el trabajo de campo, no contaban con ningún tipo de asistencia técnica para las labores ganaderas, ni mucho menos con algún tipo de subsidio. Estos planes de desarrollo buscan descentralizar las funciones estatales y responsabilizar a los pobladores locales frente al crecimiento económico y la mejoría en la calidad de vida. Esto es contraproducente en la medida en que las instituciones pueden evadir parte de sus responsabilidades al respecto, lo cual genera abandono en asistencia a los productores, muy propia de la situación de lugares como Pueblo Viejo, y, por consiguiente, bajos niveles de competitividad en el mercado, infraestructura, ingresos y calidad de vida. Toda esta problemática laboral que ahora predomina en la vereda se consolidó en buena medida luego del cierre de la mina y la empresa:

-Felipe Rojas: ¿Cuál es la situación laboral de acá de Pueblo Viejo?

-Vecino: Por este lado, pues lo que más es en la ganadería ahorita. De cultivo, ya muy poco. Todo es más o menos ganadería lo que mantienen acá por toda esta parte, de Pueblo Viejo. Porque como le había dicho, antes ocupaban mucha gente por la explotación de la piedra para la cal. -F: O sea que con relación a lo que era la mina y lo que es ahora la ganadería, el cambio en cuanto al trabajo... 
-V: No, eso cambió en más de un 80 \% por el desempleo, eso cambió mucho.

-F: ¿Y el cierre de la mina, eso fue lo que generó que la gente empezara a buscar otras opciones?

-V: Claro, sí porque de todas maneras allá había mucha gente trabajando. Tenían sus casas ahí [cerca a la mina]. (Entrevista a vecino del sector, 20 de agosto de 2012)

Según el certificado de existencia y representación legal de la Cámara de Comercio de Bogotá, la compañía explotadora de cal fue fundada en el año 1931 (Cámara de Comercio de Bogotá, 2012). El último movimiento que registra esta empresa fue llevado a cabo en 1979 y corresponde a la liquidación de la sociedad. Sin embargo, la mina siguió funcionando hasta el año de 1992, pues legalmente la figura de "liquidación" no representa un impedimento para su funcionamiento. A simple vista, se puede apreciar que la mina funcionó por más de sesenta años, por lo que no es de extrañar que para los vecinos, esta constituya un importante referente de oferta de trabajo en la región.

Por esta razón, parte de la problemática que aborda esta investigación tiene que ver con la manera como la existencia de la RBE en el mismo lugar en donde antes operaba la mina es objeto de reparo a nivel laboral para muchos de los vecinos. Este problema tiene dos ejes analíticos. En primer lugar, están las expectativas de trabajo en la RBE que expresan los vecinos y su situación frente a la cantidad, las formas de empleo y los contratos laborales ofrecidos por la FNC. La responsabilidad que se le reclama a la FNC como empleador local tiene que 
ver con la añoranza por la mina que existía en el mismo lugar que la RBE. Por su parte, si bien existen otras instituciones responsables del problema laboral en Pueblo Viejo como la Alcaldía Municipal, la Gobernación de Cundinamarca, el Ministerio de Agricultura, el Gobierno nacional, Corpoguavio, entre otros, en campo se pudo apreciar que la población local reiteradas veces asumía la responsabilidad en el cierre de la mina, la FNC y las fincas aledañas.

Solo en una ocasión se le asignaron al Gobierno nacional la responsabilidad por el cierre de la mina y el perjuicio que esto causó a nivel laboral. No se desconoce la presencia y responsabilidad de otros actores institucionales, pero su ausencia hace parte de los hallazgos en campo en donde no se tuvo la oportunidad de apreciar sus acciones, ni escuchar las opiniones al respecto por parte de los vecinos. Por otro lado, se considera que la ausencia de otras instituciones hace parte de la misma descentralización de las funciones estatales muy propia de la discusión que se plantea en esta investigación. En segundo lugar, se encuentran las disputas por el aprovechamiento de la tierra, que si bien tienen que ver con el trabajo, se abordarán en el capítulo III, pues implican otro tipo de discusiones con respecto a la forma en que los habitantes de la zona entienden los recursos naturales y su uso. Al preguntar a una vecina del sector su opinión sobre el cierre de la mina a nivel laboral, respondió:

¡Ay a nivel social sí nos perjudicaron enormemente!, porque entonces se acabó el trabajo. La gentecita empezó a emigrar, emigrar y los pocos que tenían por ahí su huertica, 
digamos su pedacito de herencia que aún no habían vendido, jum, buscar cómo vender e irse. Ya otros se fueron muriendo y ya la gente empezó a acabarse. Tan así que ya ahora somos muy poquitos los que quedamos. (Entrevista a vecina del sector, 13 de agosto de 2012)

Durante la entrevista, esta vecina expresó estar de acuerdo con la clausura de las actividades mineras en la vereda, debido al daño que estas causaban a los terrenos y al agua. Por otra parte, su reparo por el cierre, en lo que a lo laboral se refiere, expresa la necesidad de un trabajo con muy buenas condiciones, por lo que la clausura de la mina trajo, en opinión de los vecinos, perjuicios. En la expresión "porque entonces se acabó el trabajo" se considera a la mina como la fuente predilecta de empleo, al equipararla con el trabajo como tal. Dicho de otro modo, si se acaba la mina, se acaba el trabajo.

En otras conversaciones durante el trabajo de campo algunas personas comentaban que el cierre de la mina había sido duro porque era la única fuente de empleo en el sector. Así, hay un contraste entre lo que se añora (el trabajo) y lo que se repara (el daño ambiental) de la mina, en las opiniones locales. Evidentemente, esta equiparación de la mina con el trabajo es una de las causas de que se espere que en ese mismo espacio, en donde tal explotación tenía lugar (hoy la RBE), se provean numerosas y buenas fuentes de empleo.

Con todo, estas opiniones frente a la responsabilidad de la mina en cuanto al empleo hacen parte de una forma particular de recordar el pasado a partir de la situación actual. 
Las dificultades laborales de hoy en día dan pie para rememorar la época de la mina como un periodo de bonanza a nivel laboral. Sin embargo, la responsabilidad por la situación actual no recae solamente en esta empresa, pues está relacionada con problemas más profundos de la ruralidad.

El Plan de Desarrollo Municipal 2012-2015 identifica que los principales problemas económicos del municipio son: "bajos niveles de capacitación, asistencia técnica y trasferencia de tecnología", "nula promoción del desarrollo empresarial”, "baja tecnificación pecuaria”, "desempleo y migración de la población rural”, "bajas inversiones y generación de empleo", "bajos ingresos de la población económicamente activa" y "bajo nivel de apoyo al sector agroindustrial" (Municipio de Guasca, 2012, p. 34). Esto deja ver con claridad que las dificultades laborales y económicas actuales son fruto del cierre de la mina a pequeña escala y superficial, pero consecuencia de la falta de unas políticas de desarrollo rural claras y consistentes, en un nivel más profundo y amplio.

Los testimonios orales que se recolectaron en campo discrepan sobre las razones del cierre de la mina. En el testimonio que se citó al inicio de este capítulo se asegura que la explotación se acabó porque el señor Hermann Hoeck, socio mayoritario de la empresa, murió y no hubo quién siguiera al frente de la mina. Esta vecina añade que la empresa también se acabó porque el Gobierno la privatizó, así como lo hizo con muchas otras compañías, lo que para ella tenía que ver con trabas que el Gobierno ponía al funcionamiento 
de este tipo de explotaciones. Es decir, la intervención del Gobierno en contra de la mina fue un acto que fomentó su privatización, su cierre, lo que puede llevar a pensar que esta persona, a pesar de saber que la empresa era de la familia Hoeck, concebía la explotación como un empresa pública, tal vez en el sentido de pertenencia y generación de beneficio a la población local. Algunos otros vecinos plantean razones diferentes para el cierre de la explotación:

Pues se cerró porque ahí el obrerismo que había fundó un sindicato y entonces eso les quedaba muy pesado a los patrones para cumplirles con todas esas peticiones que les pedían. Y entonces ese sindicato que fundaron fue para mal de ellos. (Entrevista a vecina del sector, 13 de agosto de 2012)

-Vecino: Hasta que se acabó, se murió el doctor [Hermann Hoeck].

-Felipe: ¿Y por qué se acabó entonces?

-V: Porque él la dirigía.

-F: ¿Pero no estaban don Hendrik y don Tomás [hijos de Hermann Hoeck]?

-V: Sí, pero ellos ya no, ellos tenían minas por el otro lado, por el lado de tierra caliente. Tenían mármol, tenían mucha tierra por todo lado. Ya para qué más. Y acabaron con la empresa.

-F: ¿O sea que se acabó porque no había quién la administrara? 
-V: ... se murió el doctor, los hijos todavía no tenían así uso de razón para manejarla, entonces... cerraron eso. (Entrevista a vecino del sector, 20 de diciembre de 2012)

En este fragmento se equipara la finalización de la explotación con la muerte del señor Hoeck, como lo conciben varios habitantes del sector. Algunos otros vecinos aseguran que la mina se cerró debido a malos manejos, lo que la llevó a declinar económicamente; ya no había dinero para pagarles a los obreros y terminó quebrando:

Ahíse acabó la mina fue por, por mala administración, porque vino una señora que trabajaba de secretaria en Bogotá, en la oficina de, donde tenían una oficina que se llamaba El Apagadero creo, que era donde llevaban allá también la cal. [...] imagínese, ¿̇una señora de oficina qué va a saber de minas? Entonces ella hizo todo lo contrario, en lugar de destapar para buscar la piedra y eso, lo que hizo fue tapar y ya de un momento a otro se acabó, sí, porque ya que no había plata para pagarle a la gente, sí, mejor dicho miles de disculpas. Ya ella empezó a no darle empleo a la gente, porque que no alcanzaba la plata y por ejemplo la maquinaria que había, entonces ya con esa maquinaria ella le pagó a los que quedaban...y ya quedó prácticamente nada de la empresa, de la empresa de cal. (Entrevista a vecina del sector, 27 de agosto de 2012) 
Otra vecina comentaba, cuando se le preguntó por la situación laboral en épocas de la mina y las razones de su cierre:

Pues más bien trabajo sí lo había. Había harto trabajo. En ese tiempo sí tenían harto trabajo los obreros que ahí sí trabajaban. Eso sí tuvieron harto trabajo, sí señor. Hasta que ya se terminó la piedra y fue que ya dejaron ahí la mina quieta, que ya no salía más piedra [...]. Por lo que se acabó la piedra. Ahí ya no hubo más roca de piedras. Hasta donde estuvo la roca de piedra bien y entonces se terminó y por eso ya no trabajaron más. (Entrevista a vecina del sector, 2 de septiembre de 2012)

Esta cita expresa dos cosas. Por un lado, está la opinión de un cierre que tuvo que ver con la escasez del mineral; otro vecino aseguraba que al final ya costaba mucho sacar la piedra a causa de su escasez. Por otra parte, la cita muestra la manera como es recordada la época de la mina a nivel laboral como un periodo de abundancia de ofertas de empleo. Además, la añoranza por el trabajo en la mina y las dificultades laborales de la actualidad son aspectos expresados de la siguiente manera por la vecina citada anteriormente:

Pues cuando estaba la mina tenían más trabajo que ahora. Claro que ahora tienen, trabajo tienen, pero en cambio en ese tiempo había más trabajo por lo que la mina allí la gente más cerquita, todos los que vivían en esta vereda, porque ya todos casi se murieron de verdad, entonces tenían ahí 
su trabajo más bien. Les quedaba más cerquita para el trabajo. Entonces en ese tiempo les quedaba más fácil para los trabajadores de la mina. Ahí sí los que trabajaban ahí en la mina y los otros abajo en el horno. (Entrevista a vecina del sector, 2 de septiembre de 2012)

Las figuras 5 y 6 ejemplifican parte de las formas de trabajo en la extracción y trasporte de la piedra de cal y dan alguna idea del número de puestos de trabajo que ofrecía la mina de cal de Guasca. En la figura 5 se aprecia a 15 trabajadores sacando y cargando la piedra, mientras que en la figura 6 están usando compresores para partir la roca de cal.

Figura 5. Mina de cal en el año 1955

Trabajadores partiendo y cargando la piedra caliza (autor desconocido)

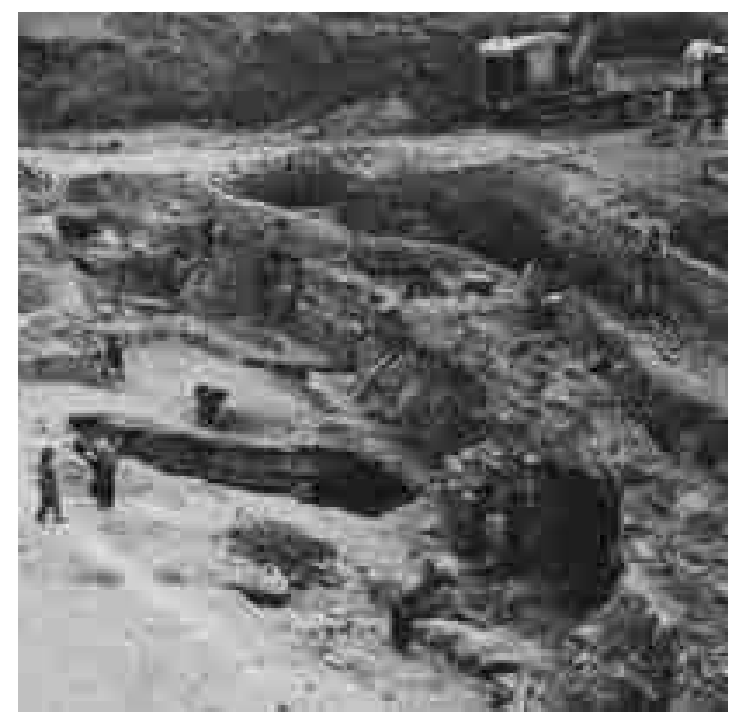

Fuente: cortesía FNC y Hendrik Hoeck. 
Figura 6. La mina de cal hacia el año 1963

Trabajadores usando compresores para partir la piedra (autor desconocido)

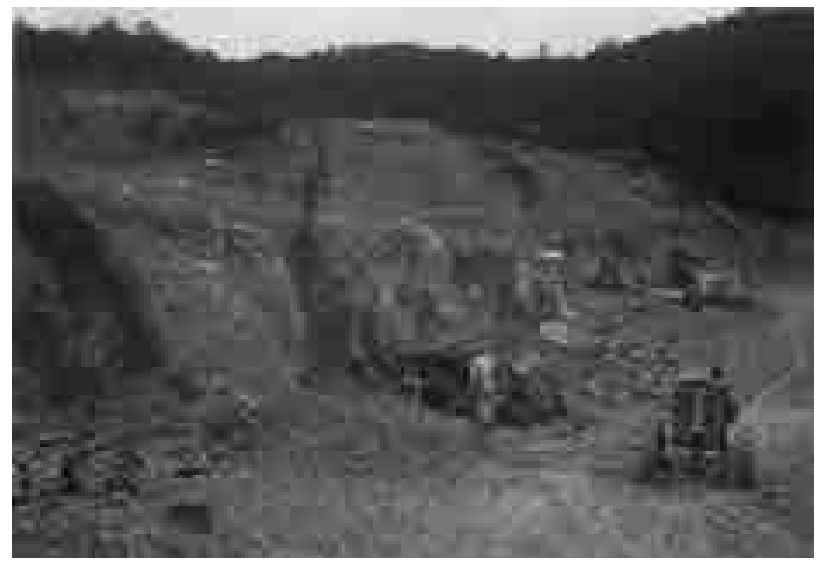

Fuente: cortesía FNC y Hendrik Hoeck.

Tal como se ha venido argumentando, la situación laboral actual no es muy bien vista por los habitantes locales y el fragmento de entrevista citado líneas atrás es una muestra de ello. En primer lugar, la cantidad de trabajos que ofrecía la mina es añorada en la época actual en donde las ofertas son limitadas y un tanto escasas. Por otra parte, esta situación de escasez de la oferta trae consigo un agravante que la vecina expresa como la cercanía del trabajo. Al no haber trabajo cerca, la gente debe desplazarse, lo que es visto como una dificultad laboral local. En cambio, en la época de la mina había dos cosas fundamentales para el trabajo en el sector: oferta y cercanía, por lo que muchos vecinos ven ese periodo como un momento de bienestar a nivel laboral, pese a sus reparos sobre lo pesado del trabajo y las afectaciones en la salud que causaba la mina. 
En contraste con parte de las opiniones de los habitantes locales que se han venido reconstruyendo, la FNC les comenta a los visitantes de la RBE que la mina fue cerrada por la toma de conciencia del señor Hendrik Hoeck frente al daño ambiental que esta causaba. En una conversación con el señor Hoeck, este comentó que a inicios de los noventa estuvo conformada en el lugar la Fundación Encenillos en conjunto con la Universidad de los Andes, cuya finalidad era proteger esos bosques y operó a mediados de la década de 1990. Esta fundación fue creada después del cierre de la mina, pero luego fue disuelta debido al auge guerrillero en la región. La trayectoria profesiona $1{ }^{10}$ y personal del señor Hoeck indica que el cierre de la mina tuvo que ver con buena parte de los factores expuestos por las distintas voces de Pueblo Viejo. La conciencia ambiental del señor Hoeck fue un factor clave, pero también la muerte de sus padres, pues no solo dejó a la empresa y la explotación sin sus principales directores y dueños, sino que produjo posteriormente una repartición de los bienes entre los tres hijos. Así, el señor Hendrik Hoeck decidió, luego del cierre de la mina, conformar una reserva natural en parte de las tierras que recibió en herencia,

10 Es biólogo de la Universidad de los Andes y de la Universidad de Múnich, hijo de los socios mayoritarios de la compañía explotadora de cal y heredero, junto con sus dos hermanos, de los predios que sus padres compraron en la región; es socio fundador de la Fundación Humedales Colombia y de la asociación Swiss Friends of the Galápagos Islands; miembro del Global Nature Fund (Alemania), Ubuntu Foundation (Suiza), Fundación Charles Darwin (Ecuador) y de la FNC; trabajó su tesis doctoral en biología en el comportamiento y ecología de los damanes, un mamífero pequeño de África, en el Instituto Max-Planck Seewiesen, Departamento de Zoología de la Universidad de Múnich (Fundación Humedales, s. f., comunicación personal con Hendrik Hoeck, febrero de 2013). 
hasta que finalmente en el año 2007 se conformó la RBE de la mano de la FNC. Por otra parte, la explotación del mineral después de tantas décadas de trabajo se fue agotando y dificultando su extracción, lo cual fue otra de las causantes de declive y posterior cierre, además del deslizamiento, la erosión y el daño ambiental que estaban sufriendo algunos terrenos.

\section{El trabajo en la Reserva Biológica Encenillo: una misma tierra, labores distintas}

Nunca ha dejado de ser una razón de asombro el hecho de que en el mismo lugar donde duró 61 años una explotación de piedra caliza exista hoy en día una reserva biológica. El asombro proviene del profundo contraste que suponen actividades como la minería a cielo abierto y la declaración de áreas protegidas. Dentro del estudio de los conflictos ambientales, propio de la ecología política y la antropología ambiental, fue objeto de interés de esta investigación indagar por cuáles son las implicaciones de la constitución de un área de conservación ambiental para los pobladores locales. Investigaciones como las de Brenner y Job (2006) y Orozco et al. (2008) trabajan temas relacionados con la constitución de áreas protegidas, en este caso, la Reserva de la Biósfera Mariposa Monarca, en México, declarada en 1980. Por su parte, Troncoso (2008) aborda la declaratoria de la Quebrada de Humahuaca Jujuy en Argentina como patrimonio natural y cultural de la humanidad como propuesta de desarrollo basada en el turismo. Estas tres investigaciones abordan el problema del desarrollo sostenible, expresado en el ecoturismo, como una de las formas de manejo de las áreas 
protegidas, en aras de mitigar el impacto ambiental, la falta de puestos de trabajo y la pobreza de las poblaciones aledañas a áreas naturales.

La región en la que trabajan Brenner y Job (2006) y Orozco et al. (2008) se caracteriza por la alta marginalidad de su población campesina e indígena y unas condiciones socioeconómicas adversas que dificultan el desarrollo local y la protección ecológica. Parte de su intención es analizar hasta qué punto esta forma de desarrollo sostenible supone bienestar económico para estas poblaciones aledañas a la reserva en contextos de pobreza campesina, falta de oportunidades laborales e impacto ambiental. En el caso de Troncoso (2008), la declaratoria patrimonial de la quebrada fue una estrategia que buscaba mitigar el impacto del desempleo por cuenta del cierre de diversas empresas a través del turismo como modelo de desarrollo.

Estos casos ponen de presente que el ecoturismo se ha convertido en una variable clave dentro de las formas de trabajo ofrecidas por las áreas protegidas. Sin embargo, el alcance de esta actividad puede llegar a ser muy limitado en lo que respecta a ofrecer medios de subsistencia a las poblaciones locales. Brenner y Job (2006) aseguran que el ecoturismo no ha sido una opción viable para estas personas, por lo que el impacto ambiental sobre los recursos ha continuado e, incluso, la pobreza no ha podido ser mitigada.

Troncoso (2008) sostiene que el turismo ambiental no ha respondido a las necesidades económicas locales porque las ganancias de este negocio se las llevan principalmente los empresarios. Por su parte, Orozco et al. (2008) cuestionan 
la existencia de un desarrollo realmente sostenible en las prácticas del proyecto ecoturístico desarrollado en la reserva que estudian, pues aseguran que no solo no ha servido para mitigar la pobreza y el impacto ambiental, sino que, incluso, las prácticas turísticas han generado mayor deterioro sobre los ecosistemas. A su vez, Hernández et al. (2005), en su análisis en busca de estrategias para mitigar el deterioro ambiental y la pobreza en cuatro comunidades marginales y empobrecidas al sureste del estado mexicano de Oaxaca, establecen una correspondencia entre ambas, en lo que han denominado un "círculo vicioso": la existencia de pobreza es un potencial generador de deterioro ambiental. En la misma línea, Orozco et al. (2008) proponen que hay una correspondencia entre uso inadecuado de los recursos del entorno y pobreza.

En Argentina, existen casos similares como los del Parque Nacional Lanín, cuya constitución propuso cambios en las actividades ganaderas de la población local, control sobre el uso de los recursos naturales e introducción de otro tipo de labores como el turismo (Osidala et al., 1992). Por su parte, en la reserva faunística del Chimborazo, en Ecuador, se propusieron modelos de desarrollo local basados en el ecoturismo como forma de manejo con un enfoque diferencial de género y la puesta en marcha de un diálogo entre las partes involucradas para la resolución de conflictos por el manejo de recursos ambientales y el trabajo (Burbano, 2005).

Para el caso de la Reserva Biosfera Maya en Guatemala, se identifican problemas relacionados con la existencia de estas zonas protegidas en áreas habitadas y en relación con el uso de los recursos naturales y las alternativas que se deben gene- 
rar a nivel económico, bienestar social y cuidado ambiental a través del desarrollo sostenible (Monterroso, 2006). Lo común a estos casos, y que es relevante analíticamente para esta investigación, es el cambio en las actividades económicas que supone la declaratoria de áreas de conservación a nivel planetario. En la mayoría de los casos, se restringen ciertas labores, mientras se propone el ecoturismo como aquella "fórmula mágica" de empleo y desarrollo para la población local. Ello supone tendencias globales sobre la manera de entender el trabajo en áreas de conservación ambiental de las que Guasca no es ajena porque, como se ha reconstruido, la principal actividad laboral en esta reserva es el ecoturismo.

El ecoturismo ha sido criticado tanto por su impacto ambiental, es decir, cuestionando su presumible sostenibilidad, como por su real posicionamiento como alternativa económica para la población. Durán (2009) y Ojeda (2012) exponen que, para el caso del Caribe colombiano, en el ecoturismo las poblaciones locales son empleadas o se les permite ejercer las labores menos lucrativas, mientras que las empresas privadas obtienen las mayores ganancias de este negocio. Además cuestionan la supuesta sustentabilidad de esta actividad económica, como ha sido desarrollada a gran escala, pues no solo genera mayores desechos que afectan al ambiente, sino que permite la realización de actividades en pro de acrecentar sus ganancias en discordancia con las políticas de conservación (Durán, 2009; Ojeda, 2012).

Estos casos tienen en común, además, la situación de falta de oportunidades laborales y de calidad del empleo, las restricciones sobre el manejo y uso de los recursos del 
ambiente y la pobreza en el sector rural. ${ }^{11} \mathrm{El}$ debate específico que surge aquí tiene que ver con la calidad y cantidad de las oportunidades laborales que puede brindar un proyecto de conservación ambiental basado en prácticas como el ecoturismo. Esto implica analizar de qué forma las políticas laborales asociadas a la conservación alteran las formas locales de relación con el entorno a través del trabajo. Si el trabajo (minero y agropecuario, en el caso de Guasca) es una forma de apropiación de la naturaleza en el área rural, su trasformación supone modificaciones sobre las formas de entendimiento y relación con el ambiente.

Los casos mencionados muestran que la constitución de áreas de conservación es una tendencia mundial en la actualidad que altera las condiciones de vida locales al restringir o cambiar los usos de los recursos del entorno y proponer nuevas actividades laborales, como sucede en Guasca. A nivel teórico, y siguiendo el enfoque de la Nueva Ruralidad, esto sugiere que actualmente en el campo lo agropecuario no es la única forma de actividad económica, pues existen otro tipo de labores relacionadas con los servicios turísticos y ambientales que han tomado fuerza (Echeverri y Ribero,

11 Según el más reciente informe nacional de desarrollo humano para Colombia, publicado por el Programa de las Naciones Unidas para el Desarrollo (PNUD), la brecha entre las áreas urbanas y rurales ha aumentado, de manera que la reducción de la pobreza en el campo ha sido menor que en la ciudad. Establece, además, que a mayor índice de ruralidad en los diversos municipios del país, mayor pobreza y menor consecución de los objetivos del milenio. Gran parte de los problemas de pobreza y desarrollo en el sector rural tienen que ver con la concentración de la propiedad, la dificultad en la generación de ingresos y la falta de empleos permanentes y dignos (PNUD, 2011). 
2002), aunque no siempre en beneficio de las poblaciones. Este enfoque teórico propende por entender la complejidad de lo que es la ruralidad, muy acorde con lo que acontece en Guasca en donde conviven diferentes actividades labores, no siempre congruentes entre sí ni libres de tensiones. En el caso de la RBE, el cambio se dio de una explotación minera y agropecuaria a una reserva de la sociedad civil administrada por una ONG ambiental.

Así como lo muestra la figura 1, la FNC emplea actualmente a seis personas, cinco $^{12}$ de las cuales son contratadas por días para la realización de actividades de aseo, cocina y como guías turísticas de los visitantes de la RBE. El otro empleo corresponde a la administración residente de la reserva, una persona que cuenta con un contrato laboral a término fijo y prestaciones sociales. Las otras cinco personas son llamadas ocasionalmente, cuando hay eventos y se reciben decenas de visitantes en la reserva, para preparar y servir los alimentos, hacer aseo antes y después de su llegada y ofrecer guías por los senderos de la RBE. Todas las labores ofrecidas giran en torno al ecoturismo como principal actividad económica desarrollada por la FNC en la RBE. Ello implica que los guías deben ejercer algunas nuevas formas de trabajo

12 Adicional a estos cinco trabajadores, durante unos meses la FNC empleó los fines de semana a una pareja de hermanos adolescentes que hacían labores de mantenimiento de las instalaciones de la FNC en el sector, servicios generales, recibimiento de los turistas, y se estaban preparando para ser guías turísticos. Estos jóvenes eran estudiantes de la IED El Carmen, sede El Salitre, y residentes de Pueblo Viejo. Después de unos meses de trabajo, parece que la FNC no estuvo a gusto con la labor desempeñada por estos jóvenes, por lo que no continuaron con su labor. 
(interactuar con turistas, cocinar para ellos, limpiar sus desechos y explicarles sobre la fauna y la flora), así como nuevas maneras de entender el entorno (aprender nombres y denominaciones científicas).

En las observaciones en campo, se pudo apreciar que ese trabajo en ecoturismo no era lo suficientemente estable. Se constató que el actual jefe de reserva, en comparación con los anteriores, y en opinión de los vecinos, ha traído mayor número de visitas, por lo que una o dos veces a la semana se hacen actividades en la reserva en las que se requieren los servicios de estas personas que trabajan por días. Sin embargo, de los siete días de la semana, solo entre uno y tres estas personas son empleadas para hacer trabajos en la reserva, por lo que esta labor no se convierte en una actividad que les permita sobrevivir; más bien es un ingreso complementario a otro tipo de actividades laborales principales, como la ganadería.

En las observaciones que se hicieron de los eventos que llevaba a cabo la FNC en el lugar, me percaté de que empleaba en promedio tres trabajadores locales, distribuidos entre guías, cocina y aseo. Eventualmente, la FNC ha brindado trabajo a los maestros de obra locales en actividades de remodelación de sus instalaciones o de arreglos, pero estas labores han sido ocasionales y, en su mayoría, se concentraron en el inicio de la reserva en la que se efectuaron algunas obras de adecuación de las instalaciones del FNC en el lugar para las actividades a desarrollar, entre ellas el ecoturismo. Otro tipo de trabajo en el que la FNC ha empleado a los pobladores locales ha sido en la plantación de árboles y su posterior 
mantenimiento (conocido comúnmente como "plateo"), pero no han sido labores frecuentes ni regulares.

En contraste con lo que fueron los años de la mina, la FNC no ofrece empleos de la misma manera en cuanto a cantidad y calidad. En suma, para los habitantes de la zona, la RBE no ha representado una alternativa laboral en medio de la falta de opciones de empleo en el sector:

Mire que la gente le toca salir, más que todo la juventud, a la mayoría les toca salir a buscar trabajo porque acá no hay. Acálo único asíes, pues lo ganadero [...] Juventud acá como tal ya no hay porque oportunidades de empleo no hay. Y si hay, no es nada seguro. Por ejemplo, en las fincas los administradores se creen como los dueños y sí, tratan a la gente mal. A veces la gente se va por eso. Vienen, van porque el trato no es bueno. Sí, la gente trata de dar lo mejor de sí, pero pues por los hijos, por el trabajo y todo, por necesidad ¿no? Pero pues el trato de los jefes como tal no es bueno y les toca irse. Lo digo en el caso de las fincas que están acá alrededor. Pero como tal pues la parte laboral acá me parece que no es buena. Por eso es que la gente tiene que irse de acá. Y los que, o sea, están acá es porque ya tienen su casa, tienen algo seguro, ¿̇í́? Aquí no hay oportunidades de empleo. Hubiera flores o ¿qué sé yo? Mm..., fresas o eso, pero acá no. Pues la Fundación [Natura] sí, pero igual ahí, ahí qué, abi no hay trabajo. (Entrevista a vecina del sector, 27 de agosto de 2012. Cursivas del autor) 
Esta vecina considera, en medio de sus reparos por la situación laboral del lugar y la migración que ello ha supuesto de la juventud local, que la FNC no ofrece mucho trabajo, pues considera que en la RBE no hay mucho por hacer. La baja oferta laboral en la reserva tiene que ver con varios factores. En primer lugar, el uso de los recursos naturales que proponen en reforestación y cuidado de los bosques entra en conflicto con los usos "tradicionales" locales que pueden llegar a ofrecer mayor trabajo, pero cuyo impacto ambiental puede ser mayor (el problema de los usos del suelo en la RBE se abordará en el capítulo III). En segundo lugar, la poca oferta de trabajo que brinda la FNC tiene que ver con la forma en la que se desarrollan las actividades ecoturísticas en la RBE. En general, las labores de guías son ejercidas no solo por habitantes locales, también se emplean personas foráneas, principalmente de Bogotá. Esto supone tensiones con la población local:

Aquí debían ocupar la gente. Debían de rotarla, "bueno usted va hacer esto, usted va hacer esto, en ciertos días va ocupar en [...]" así. ¿Lo ve? Entonces, esa reserva sí estaría dándole beneficio a las personas del mismo municipio, a las personas del mismo sector. Pero no, prácticamente no. No porque digamos porque no traigan gente de otro lado, no. Pero es que realmente tiene más obligación, tiene más derecho la gente de acá. (Entrevista a vecino del sector, 3 de septiembre de 2012) 
Los vecinos del sector consideran que las personas del lugar tienen más derecho a trabajar en la RBE que las personas foráneas. Esto no solo demuestra un arraigo territorial, sino un reparo a que la FNC traiga guías externos para las actividades en la RBE. Y es que sumado a la situación laboral del sector, evaluada por los vecinos como mala, en especial por la baja oferta laboral y la poca estabilidad que existe en las fincas contiguas, la FNC no está cumpliendo con buena parte de sus expectativas laborales. En otra entrevista con dos vecinos, dieron las siguientes respuestas al respecto:

-Felipe Rojas: Porque tengo entendido que también a veces han traído guías es de Bogotá.

-Vecino 1: Imagínese habiendo gente acá, prácticamente capacitada.

-Vecino 2: Una persona de Bogotá qué historia le va a contar a uno.

-Vecino 1: O es que yo creo que hasta ni se saben el nombre de los árboles o por qué, si este da unos frutos que se puede comer uno o no. (Entrevista a ganaderos locales, 8 de septiembre de 2012)

Su reparo está mediado, al igual que el anterior, en considerar que las personas de la vereda deberían hacer el trabajo. Es más, estos vecinos argumentan por qué deberían hacerlo, aducen a las capacidades que tienen en cuanto al conocimiento de su entorno y la historia del lugar. Toledo y Barrera (2008) sostienen que las poblaciones locales tienen un conocimiento de su entorno debido a años de experimentación, interacción 
con el ambiente y procesos de trasmisión nemotécnica de estos saberes. Si bien su argumento parte de consideraciones esenciales sobre lo étnico y tradicional, extendiéndolo a grupos no marcados étnicamente, es pertinente. En el caso de Guasca, adquiere relevancia pensar cómo, desde esta opinión citada, existe un desconocimiento de los saberes locales en las prácticas ecoturísticas promovidas por la FNC.

En cuanto al trabajo, este desconocimiento se basa en traer guías externos que carecen del saber local sobre el entorno, pero que son empleados por ser biólogos, saneadores ambientalistas o tener relación con estas áreas del conocimiento. Esto sugiere que los discursos ambientales pueden implicar tensiones constantes con los conocimientos locales y la apropiación del lugar. Las comunidades se ven imbuidas en luchas y diálogos con procesos ambientales globales y políticas de administración de los recursos naturales que intervienen sobre el entorno y las formas de vida. Además, los conocimientos son jerarquizados, no en vano los guías deben aprender los nombres científicos. Si bien esto no quiere decir que no se usen los nombres comunes, se les da una mayor validez intelectual a los científicos en las labores ecoturísticas.

Parte de la expectativa local de trabajo en la reserva tiene que ver con la percepción que muchos vecinos tuvieron de esta en el momento de su inauguración, pues gran parte de ellos expresaron que les habían comentado que la idea de constituir la RBE era brindar trabajo a la población local. Sin embargo, no deja de ser problemático que la población asuma que la FNC tiene gran parte de la responsabilidad 
de lo ocurrido y no se cuestionen a otras instituciones como la Alcaldía Municipal o el Gobierno nacional como responsables de la situación laboral de la vereda. Muchos esperan que esta gran porción de tierra, esta finca, como muchos la denominan, y su nuevo administrador (la FNC), continúe siendo un medio de producción que genere empleo, como históricamente lo fue la mina, sin cuestionar cuál es la responsabilidad de otros actores privados y públicos al respecto.

Parte del proyecto de vinculación de los habitantes locales como guías turísticos surgió en el año 2008, por iniciativa de dos estudiantes de Biología de la Universidad Incca de Colombia, que estaban haciendo su tesis de grado en la reserva bajo el apoyo de la FNC y cuyo tema central fue el estado de la avifauna en la RBE. En este proyecto, se "conformó un grupo de eco-guías de ocho personas habitantes de la vere$\mathrm{da}$, los cuales fueron capacitados, con el fin de concientizar a las personas y ofrecer otras formas de trabajo" (Camargo y Moreno, 2008, p. 60, cursivas del autor).

Parte de la intención de este programa consistía en la capacitación de los habitantes locales en el cuidado ambiental. La palabra "ecoguías" sugiere un concepto interesante sobre la manera de entender la labor que debían desarrollar estos vecinos. No solo estarían capacitados para guiar a los visitantes, sino que serían ellos mismos educados para aprender a conservar la reserva y generar conciencia ambiental. El trabajo como ecoguías gira alrededor del ecoturismo y supone la intervención sobre la forma en que los sujetos locales se relacionan y entienden la naturaleza. Las palabras “capacitar” y "concientizar" presentes en la propuesta de 
estos tesistas sugieren una forma de intervención sobre los sujetos para dejar de ser únicamente campesinos, mineros o jornaleros y convertirse en ecoguías.

Este trabajo, en palabras de una pobladora local capacitada en este proceso, no consistía en ser un tipo de guía cualquiera, sino en informar sobre lo que había en el lugar, esto es, sobre la fauna y flora local. Los ecoguías hicieron parte de una iniciativa que si bien no tuvo mayor alcance, es una muestra de las formas en que los proyectos de conservación entienden la labor, las capacidades y el papel de las poblaciones locales en las áreas protegidas. Son una forma de crear sujetos bajo ciertas características, separados del común de las otras personas a través de un proceso de educación.

El trabajo como ecoguías crea una nueva forma de labor, un nuevo sujeto que debe hacer ciertas actividades asociadas al ecoturismo y el cuidado ambiental. Esta labor representa algo novedoso en el lugar, nunca antes practicada como actividad económica. Parte de la novedad consiste en que su base no son las actividades agropecuarias o mineras características de la vereda, sino la necesidad de capacitaciones en temas relacionados con el ambiente y su cuidado.

$\mathrm{Mi}$ argumento consiste en que la educación en temas ambientales para el ejercicio de esta actividad modifica parte de, o busca modificar, la percepción que tienen los habitantes sobre la naturaleza. No cualquiera podía ser ecoguía a partir de sus conocimientos del lugar, debía pasar por un proceso educativo en el que se le imprimieran unos conocimientos y una toma de conciencia particular. Esto es, a todas luces, una forma de intervención y creación de unos sujetos particulares, 
en este caso ambientales, ${ }^{13}$ pues la actividad del ecoguía, como estaba planteada, no solo era laboral, sino que implicaba un cuidado constante de la naturaleza en la cotidianidad. Una vecina expresaba lo siguiente sobre su trabajo en la RBE:

Pues eso es bonito. $\mathrm{O}$ sea es una experiencia bonita porque uno aprende, empezando porque uno vivía acá y no sabía los nombres de los árboles nativos, eso sí aprende uno bastante. (Entrevista a habitante local, 3 de septiembre de 2012)

Este fragmento, además de mostrar el agrado de algunas personas que han trabajado como guías en la RBE, ejemplifica parte de las formas en que los procesos políticos ambientales (en este caso de ofrecimiento de trabajo en áreas de protegidas) modifican e intervienen las maneras de pensar, conocer y entender la naturaleza. Esta vecina expresaba que no conocía los nombres (científicos) de las plantas nativas, y aduce su importancia para la aprehensión del entorno y el desempeño en el trabajo como ecoguía. Algunos otros vecinos consideran

13 Este concepto tiene que ver con la construcción que el ambientalismo hace de unos individuos y grupos humanos como tendientes a la conservación y el cuidado ambiental. Desde una perspectiva foucaultiana, Agrawal (2005) esboza este concepto de producción de sujeto ambiental para denotar cómo las tecnologías de gobierno y poder ambiental crean unos sujetos determinados acordes con las intenciones de conservar la naturaleza. Parte de la crítica a este concepto versa sobre la no automaticidad de la producción de sujetos, esto es, considerar que los individuos acogen pasivamente estas tecnologías de gobierno y son producidos como ambientales de forma automática y total. Uno de los autores que propone esta crítica es Cepek (2011) en su texto Foucault in the Forest: Questioning Environmentality in Amazonia. 
que están bien capacitados para ejercer esta labor de ecoguías, mientras que otros expresan que les hace falta mayor capacitación y una biblioteca para consultar, en especial sobre la flora y la fauna para realizar las explicaciones a los visitantes. Todo este cambio en las formas de aprehensión del ambiente no es inmediato, sino que hace parte de una serie de tensiones y negociaciones. Así, los procesos políticos y económicos derivados del ambientalismo aterrizados a escalas locales suponen tensiones entre formas de conocer y conceptualizar el ambiente. Las lógicas científicas intervienen las maneras de conocer y entender la naturaleza que han ejercido estas poblaciones por generaciones. En otras palabras, en este escenario se presentan tensiones por los significados de la naturaleza y su conocimiento (Escobar, 2005).

De las ocho personas capacitadas para esta labor, solo dos la ejercen actualmente con regularidad, es decir una vez a la semana por lo menos. Algunas de las personas restantes nunca fueron llamadas a ejercer el trabajo, mientras que otras se retiraron por falta de un contrato fijo, de regularidad del trabajo ofrecido por la FNC (lo cual en muchas ocasiones interfería con sus labores en la ganadería), por falta de un salario fijo o por motivos personales:

-Vecina: Pero ya le digo, yo me retiré fue por lo que ahí sí no era un sueldo fijo. Y después ya me puse a trabajar en el ordeño entonces ya llega uno muy cansado para ponerse en esas carreras de que corra pa' un lado y corra para el otro. -Felipe Rojas: Y sumercé me dice que no siguió porque la llamaban cada mucho tiempo. 
-V: ya últimamente me estuvieron llamando, pero ya no tuve tiempo porque ya me metí a trabajar en una parte donde, pues donde uno tiene un sueldo fijo. Porque como allá no era sueldo, o sea era una vez al mes o por allá cada dos meses. Entonces ya me metí a trabajar en una parte donde estoy trabajando, estoy ganado un sueldo fijo que sé que me va a llegar quincenas. En cambio allá no tenía esa posibilidad.

$-\mathrm{F}:$ ¿Y sumercé dónde está trabajando?

-V: pues en el ordeño, pero de todas maneras es un sueldo fijo que uno tiene. Entonces ya no me queda tiempo porque yo ya llego aquí, toca estar, cuando está trabajando en la reserva uno tiene que estar allá a las siete y media de la mañana, arriba, pa' esperar ahí sí los visitantes y yo estoy llegando aquí a las ocho. Entonces mientras llego y me desayuno y no para estar en esas carreras ya estoy muy vieja. Ya no.

-F: ¿Y entonces sumercé en qué condiciones hubiera seguido trabajando ahí?

-V: Que hubiera sido un sueldo fijo. Que uno le dieran, por ejemplo, le dieran a uno sus dotaciones, por ejemplo las botas, el uniforme [...]. (Entrevista a vecina del sector, 3 de septiembre de 2012)

Otro de los debates que subyace a propuestas como la de los ecoguías tiene que ver con una conservación incluyente contra una excluyente. En este caso, este pequeño proyecto de dos estudiantes que contaron con el apoyo de la FNC representó, de alguna manera, una apuesta de inclusión 
de los pobladores locales en el proyecto de conservación. Campos y Ulloa (2003) abogan por la importancia de los pobladores locales en el manejo de los recursos naturales junto con otro tipo de actores gubernamentales y no gubernamentales. Aseguran que la solución a los problemas ambientales no solo debe ser desde el trabajo de la academia, sino desde los saberes y las prácticas de aquellos actores que están todo el tiempo relacionados con los recursos naturales. Esto plantea la necesidad y el derecho de inclusión de los pobladores locales en el manejo de recursos naturales en áreas protegidas.

En consecuencia, el proyecto de los ecoguías si bien fue una forma de inclusión incipiente, se encontraba bajo preceptos que no reconocían del todo los saberes locales sobre el entorno, pues la capacitación fue en una sola vía (de la FNC hacia la población). En efecto, no fue una propuesta efectiva de involucramiento local en el manejo de la RBE, pues no implicaba la toma decisiones y la concertación de planes de manejo, elementos clave para la participación local en el manejo de zonas de conservación ecológica.

Por consiguiente, estos propósitos de inclusión y trabajo de los ecoguías, planteados por los dos estudiantes, no se han consolidado. En primer lugar, la baja participación de la población en general en estas labores es un factor en su contra. Si bien existe interés por parte de la población en relacionarse con la RBE y hacer propuestas de desarrollo de actividades económicas allí, son muy pocos los pobladores que han comunicado esas inquietudes a la Fundación, debido a la falta de canales establecidos de comunicación periódica entre las partes. 
Las personas del sector se comunican con la FNC a través del administrador residente y el jefe de la RBE en conversaciones casi siempre relacionadas con temas de venta de pastos o trabajos ecoturísticos. De resto no hay mayor interacción entre ambos actores, y en las pocas veces en las que se han comunicado, estas propuestas no han salido a flote de manera efectiva por dificultades de parte y parte. En segundo lugar, el proyecto de los ecoguías no ha sido una opción de trabajo que pueda reemplazar otro tipo de labores, como se ha venido exponiendo. En tercer lugar, no ha habido más capacitaciones y se ha pasado de una intención de inclusión de los habitantes locales como guías a emplearlos como mano de obra para el aseo y la cocina, por lo que queda un poco de lado la labor del ecoguía propuesta.

Casos como los del Parque Nacional Natural Utría y el Parque Nacional Natural Corales del Rosario y San Bernardo expuestos por Rubio et al. (2000) y Durán (2009), respectivamente, muestran cómo se incluye a la población local en proyectos que fomentan usos sustentables de los recursos del entorno, fundamentales para la supervivencia social y ambiental, acompañados de diagnósticos e investigaciones de la mano de los conocimientos locales. Estos autores aseguran que muchos de los declarados parques naturales o áreas protegidas han desconocido la presencia de pobladores locales y sus características socioculturales, quitándoles el control sobre sus territorios y recursos naturales, que son parte de su economía y cultura.

En el caso que presenta Durán (2009), se establecieron proyectos ecoturísticos para incluir a la población luego 
de un periodo de desconocimiento y estigmatización de los pobladores locales y sus usos de los recursos naturales. Por su parte, Rubio et al. (2000) abogan, en buena medida, por superar las disputas que supone la superposición de los territorios de poblaciones locales con áreas de conservación a través de políticas de participación, inclusión y concertación. En Guasca, la idea de incluir a la población en la protección y el manejo de los recursos naturales por medio del trabajo, dentro y fuera de la RBE, hace parte de un ejercicio incipiente de inclusión, mas no de participación efectiva, en el manejo ambiental. Además, su alcance, incidencia y permanencia como proyecto permanente ha sido insuficiente.

Esta participación incipiente implica la subordinación de la población a una entidad externa. Para poder ejercer autonomía sobre su territorio, deben discutir con un actor que si bien posee la propiedad de unos terrenos, no es una habitante del lugar, lo cual es sumamente problemático. Aunque el trabajo es una forma de contacto entre la población y los funcionarios de la FNC, para que haya una participación efectiva, es clave y necesaria la existencia de planes de concertación y toma de decisiones en conjunto. No deja de ser problemático que el ecoturismo sea solo una de la formas de establecer contacto entre áreas protegidas y comunidades y que la participación que se les dé solo sea en el marco de tener acceso a parte (generalmente es muy poca) de los beneficios económicos que genera el ecoturismo, como sucede en el caso de Guasca. Es clave trascender de la relación patrón-empelado y no asumir que la vinculación a actividades ecoturísticas sea una forma total de empoderamiento de 
las comunidades, más bien puede tornarse en coerción, pues al ser empleados, se ven abocados a asumir lo que sus jefes les proponen sin mucha posibilidad de interpelarlo.

En el caso de la RBE, las personas que han trabajado con la FNC, ya sea como concesionarios que compran pastos o empleados directos, tienen mayores posibilidades de diálogo con la ONG y de expresión de sus sugerencias frente al manejo de los recursos ambientales. Con todo, este ejercicio de diálogo está por construirse en la RBE, pues hace falta la institucionalización de espacios de participación y que las opiniones expresadas por estos pobladores tengan mayor peso en las decisiones que se toman en la RBE, es decir, que trascienda de la relación patrón-empelado que impide la participación efectiva, y se vea a las personas, más que como trabajadores, como población que tiene el derecho de ser partícipe activo en la toma de decisiones.

Sin embargo, algunos vecinos del sector consideran positivo que la FNC les haya brindado la oportunidad de trabajar allí, esto es, que haya tenido en cuenta las personas de la vereda. Algunos expresaban que les parecía bueno el trabajo de guías que habían desempeñado allí porque aportaban con lo que sabían y aprendían de la gente que venía de visita a la reserva.

En un artículo titulado "Reimaginar la ecología política: cultura/poder/historia/naturaleza”, Aletta Biersack (2011) traza un recorrido genealógico de la ecología política. Parte de su propuesta consiste en esbozar los intereses actuales de este campo de estudio, siendo uno de ellos la consideración tanto de la agencia como de las determinaciones estructu- 
rales. En medio de los conflictos ambientales, los diferentes actores presentes en ellos toman posiciones, discursos y prácticas que son muestra de su agencia.

Así, los habitantes de Pueblo Viejo no asumen pasivamente los usos propuestos por la FNC sobre las tierras que conforman la reserva (problema que será abordado en el capítulo III), ni tampoco las opciones laborales y actividades realizadas por la FNC. En general, las personas que han trabajado en la RBE como guías consideran que este trabajo les permite aprender sobre la fauna y flora nativa y aportar con sus conocimientos. Aunque están de acuerdo con el pago, reparan sobre la regularidad del trabajo y el hecho de que traigan guías de Bogotá. Ven en este trabajo un ingreso complementario, mas no principal, porque el dinero que aporta, debido a la poca regularidad de esta labor, es muy bajo como para sobrevivir. Un trabajo regular, con condiciones salariales y de contrato estables en la RBE, podría trascender en una opción laboral efectiva para suplir las necesidades de trabajo locales.

Por su parte, esta agencia se hace evidente en las propuestas locales para generar mayores fuentes de trabajo en la RBE. En alguna ocasión, una vecina tuvo la propuesta de vender productos caseros en la RBE para ofrecerlos a los turistas. La propuesta consistía en elaborar yogures caseros y venderlos a los visitantes de la RBE. La vecina propuso esta idea como una oportunidad de generar ingresos extra para su familia. Sin embargo, por diversos factores, entre ellos la dificultad de esta familia para cumplir con el requisito de registro sanitario del producto, la propuesta no se llevó a cabo. Esta 
idea de vender productos a los turistas ha sido recurrente entre los vecinos. Algunos proponen, por ejemplo, la venta de almuerzos por medio del montaje de un restaurante:

Si ellos continúan digamos con su proceso de ecoturismo, pues el trabajo sería en eso. En guías. Qué más. A no ser que en algún momento monten por abíun restaurante bien grande y necesiten empleados. Porque ¿qué más puede? Ah también pueden de pronto algún este de artesanías, y qué sé yo para tanta gente que viene. Eso suele haber en los parques así y en los lugares turísticos. Esto se viene convirtiendo en un lugar turístico. (Entrevista a vecina del sector, 13 de agosto de 2012, cursivas del autor)

En otra entrevista, ante la pregunta de cómo se podría ofrecer más trabajo en la reserva, comentaban:

Pues no sé, a esa reserva le hace falta como un buen restaurante, como una caseta donde vendan golosinas. Pero donde tengamos la oportunidad, digamos, que yo quiero colocar mi negocio y le den a uno la oportunidad de colocarlo. Así toque dar alguna parte a la Fundación, pero que lo dejen trabajar a uno. Porque nosotros propusimos todo eso. Cuando la cabalgata, que para colocar la cabalgata y eso y mi esposo compró los caballos y no, nunca, o sea fue como dos veces nada más y nunca lo volvieron a llamar más. (Entrevista a habitante local, 8 de septiembre de 2012, cursivas del autor) 
Otro tipo de propuestas versan sobre la venta de productos orgánicos y la generación de microempresas:

Acá pueden poner una microempresa de cualquier cosa. Como es una cosa de naturaleza, podían tener una cosa de hortalizas, de todo eso, y ahí había empleo, ahí había venta, por decir algo. Porque son, no van a ser plántulas, hortalizas químicas, sino orgánicas. Entonces imagínese cuánto se está perdiendo ahí. Se podía fundar una cosa de esas. Ahí habría empleo. Sí señor, es que eso, yo no sé si lo pensarán hacer o hasta ahora se está organizando. (Entrevista a vecino del sector, 3 de septiembre de 2012)

Para muchos de ellos, la reserva no puede ofrecer muchos empleos porque, según su percepción, ahí no hay mucho para hacer. En este sentido, la opción que plantean varios vecinos es la creación de nuevas actividades económicas que se articulen al ecoturismo. Estas propuestas expresan un acuerdo de los vecinos por las actividades turísticas desarrolladas en la RBE, pues las reconocen como labores principales que se pueden desarrollar allí, dados los usos de los recursos naturales propuestos por la RBE que impiden otro tipo de actividades.

Durante el trabajo de campo y las entrevistas, las personas no expresaron mayor desacuerdo con este tipo de actividades ecoturísticas que desarrolla la FNC. Con todo, existen algunos reparos y tensiones que versan sobre la manera como se usan los recursos naturales, en especial el suelo, durante estas actividades que se analizarán en el capítulo III. 
Más bien, en cuanto al turismo desarrollado en la RBE, estas opiniones citadas reflejan unas propuestas para mejorarlo en pro de la generación de mayores ingresos y opciones de trabajo para la población local.

Aquí yace el debate sobre los alcances del ecoturismo como propuesta económica viable para las poblaciones aledañas a áreas protegidas y sus implicaciones en la reconfiguración del espacio y la naturaleza. Mientras se cambian los usos de los recursos del entorno y el espacio es definido como zona de conservación privada en donde los elementos biofísicos toman valor económico en sí mismos bajo el discurso de la biodiversidad, se propone el ecoturismo como actividad sostenible que, se supone, está en concordancia con los intereses de la conservación. Sin embargo, esta actividad genera menores ingresos, escasos puestos de trabajo y cambios en las formas de entender y usar el entorno. Además, algunos autores la consideran como una forma de conservación neoliberal, esto es, que se encuentra bajo la lógica de la acumulación y la privatización (Ojeda, 2012).

En Guasca, esta lógica es visible en las diferentes formas de la restricción del uso de los recursos naturales a partir de la declaratoria de un área protegida privada, además de su relación con lógicas de acumulación del sector privado, como dar valor económico a porciones de bosque, obtener pagos por servicios ambientales, cobrar por la siembra y mantenimiento de árboles, entre otros, cuyos beneficios no llegan a la población local. Es un área protegida en la que los actores locales no han tenido participación efectiva, en parte por su condición de ser una propiedad privada. 
Las cabalgatas mencionadas en uno de los fragmentos citados hicieron parte de un proyecto que plantearon unos vecinos del sector que, según ellos, no obtuvo mayor resultado. Aseguraron que el jefe, de ese entonces, de la RBE les había dado el beneplácito para realizar cabalgatas con los turistas desde el sector de El Salitre, punto en el que empieza el ascenso hacia Pueblo Viejo y, por consiguiente, hacia la reserva. La idea consistía en llevar a los turistas a caballo, y no en buses o en carros particulares, como sucede a menudo, por los cinco kilómetros que hay desde el sector de El Salitre hasta Pueblo Viejo.

Estos vecinos comentaron que este servicio funcionó unas pocas veces y que luego la actividad no se volvió a desarrollar, pues la FNC nunca los llamó para ofrecerlo nuevamente. Por consiguiente, tuvieron que vender los caballos que habían adquirido por cuenta propia para el desarrollo del servicio. En una conversación con el jefe actual de la RBE, este comentó que posiblemente esta actividad no se siguió desarrollando "por falta de mercado"; aseguró que se seguía ofreciendo, pero no había demanda. Esto demuestra cómo las condiciones de mercado tienen influencia y se relacionan con las actividades ecoturísticas, el trabajo en la RBE y el uso de los recursos naturales por su parte, las opciones de poner un restaurante y vender comida tienen un componte interesante que se hace visible en la división del trabajo por género en el sector (tabla 1). 


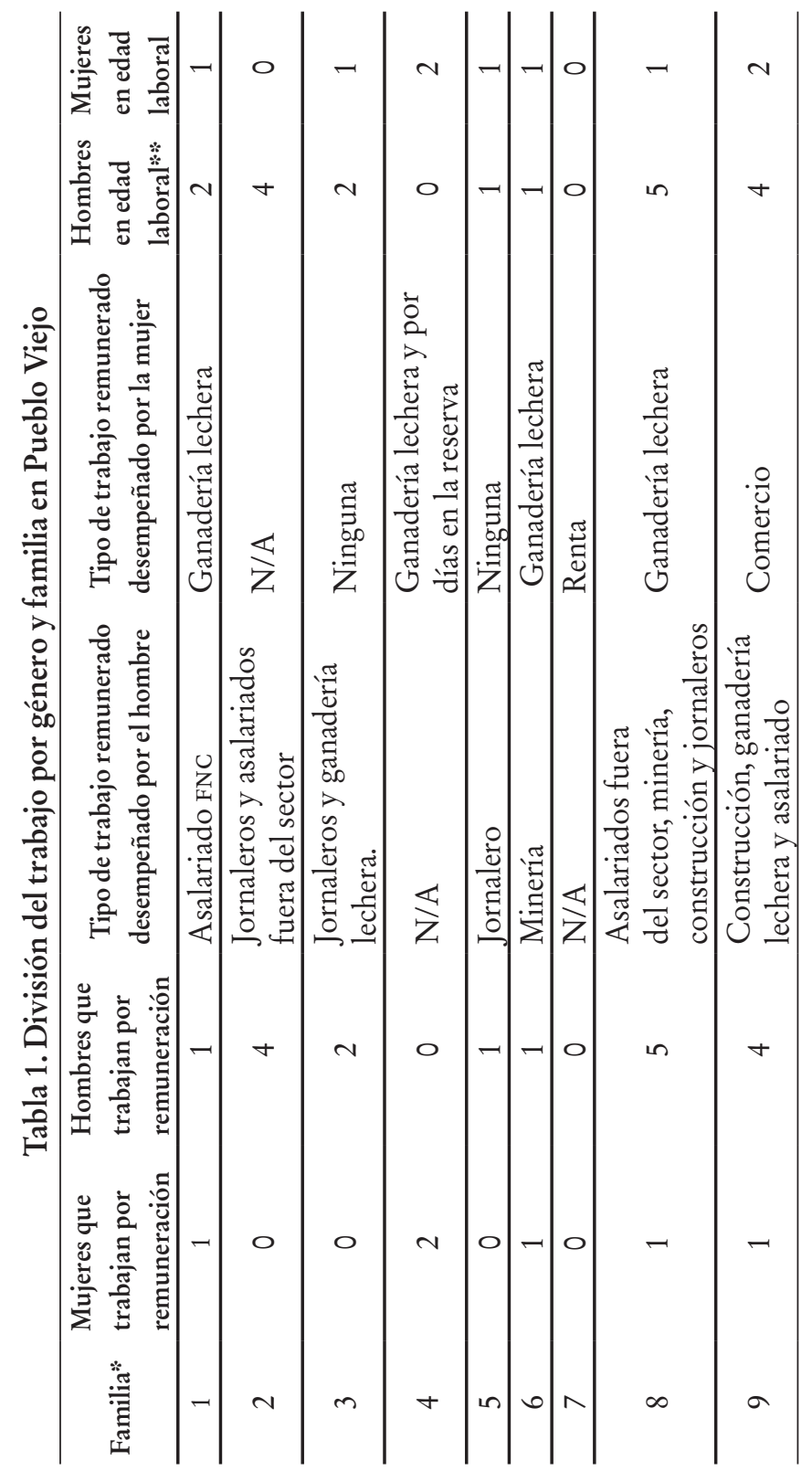


Felipe Rojas Arias

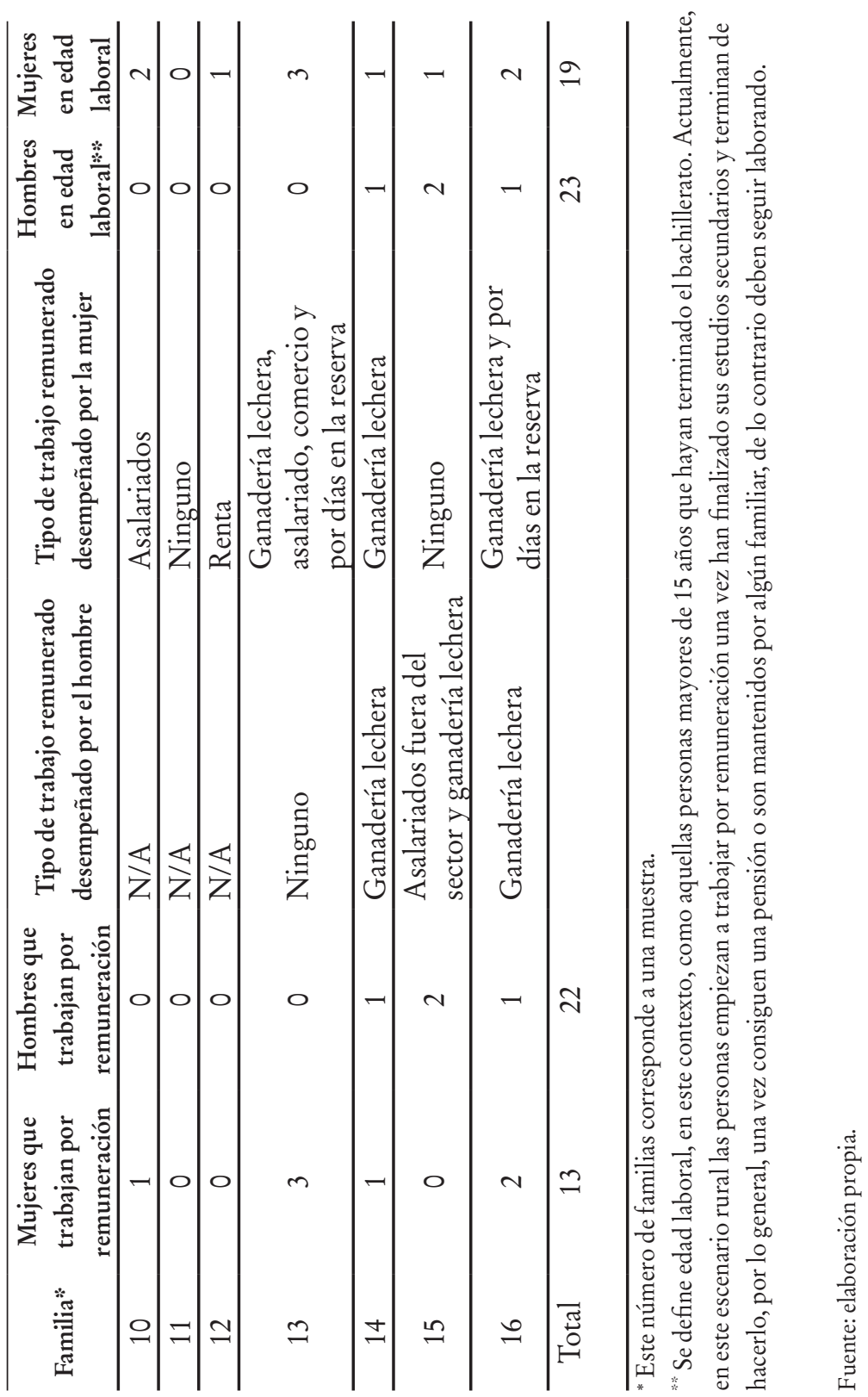


De las 19 mujeres en edad laboral, 13 ejercen alguna labor remunerada. Se hace la salvedad de la obtención de ingresos, pues todas las mujeres se desempeñan en labores y trabajos del hogar no remunerados como cocinar, lavar, limpiar la casa, cuidar a los niños, cuidar animales domésticos para autoconsumo (como gallinas y vacas lecheras) y atender la huerta casera de autoconsumo. Por su parte, de los 23 hombres en edad laboral de las familias de Pueblo Viejo, 22 ejercen algún tipo de labor remunerada. Entre las mujeres que desempeñan alguna labor remunerada, cerca de 10 trabajan en labores de ganadería lechera y 5 en la RBE. Por su parte, de los hombres que trabajan, cerca de 7 se desempeñan en ganadería lechera y solo uno en la RBE.

Es una tendencia en el sector que en los hogares en donde solo trabajan mujeres estas se dediquen a la ganadería lechera, debido a que no es bien visto que laboren como jornaleras en fincas, pues este trabajo es considerado muy pesado para ellas. Incluso en los hatos ganaderos no emplean a las mujeres para las labores de ordeño, pues atender a una gran cantidad de reses es considerado como un trabajo no apto para ellas. Esto se ve reflejado en que las mujeres que trabajan de manera independiente en ganadería lechera no tienen más de 7 vacas.

Si bien hay hombres que practican la ganadería y se dedican a ella, es más común que sea un trabajo de las mujeres, pues se convierte en una opción de vida para ellas a falta de otras alternativas acordes a sus roles de género. Los hombres tienen otras opciones en fincas como jornaleros e, incluso, les resulta más fácil trabajar fuera del sector, pues no tienen 
la obligación cultural de atender el hogar y cuidar a los niños. Las pocas mujeres que son empleadas en fincas lo hacen porque la unidad familiar adquiere un contrato con el dueño del predio para ser sus concertados. El sueldo se le paga al hombre de la casa y las mujeres e hijos son vistos como colaboradores de los hombres en las labores de la finca.

Por esta razón, las mujeres que pretenden trabajar a cambio de una remuneración requieren de un empleo en el sector. Es aquí cuando la FNC y la RBE adquieren relevancia en la división del trabajo por género en Pueblo Viejo. Algunas mujeres del sector consideran, por las razones anteriormente expuestas, que es necesario para ellas un trabajo cerca, que no sea considerado pesado (dado que ejercen demasiadas labores domésticas) y les permita seguir viendo por su hogar e hijos, pues es su labor la reproducción social. Según la tabla 1, de las 6 personas que desempeñan alguna labor con la Fundación, 5 son mujeres. Estas mujeres trabajan por días haciendo labores de aseo, cocina y guianza cuando vienen visitantes a la RBE. Sus labores en la reserva se ajustan culturalmente a las formas de trabajo consideradas femeninas en el sector: no son vistas como pesadas, quedan cerca al lugar de vivienda y tienen que ver con labores del hogar como hacer aseo o cocinar.

Así, las propuestas para generar mayor trabajo en la RBE tienen que ver, en gran medida, con la situación de falta de empleo para las mujeres del sector que se ajuste a sus pautas culturales de trabajo femenino. Otro tipo de estudios han demostrado que las mujeres están ligadas a la esfera doméstica y por eso las labores remuneradas que ejercen están 
muchas veces acordes con esta obligación de atender los oficios del hogar y los roles de género, como por ejemplo la ganadería en pequeña escala para el caso andino (Cavalcanti y da Mota, 2003; Meertens, 2000).

El trabajo en el sector de Pueblo Viejo se encuentra en una situación difícil. Las opciones laborales son escasas, por lo que las personas deben salir a buscar trabajo por fuera del sector. Esto explica la baja tasa de desempleo de la vereda, pues la emigración de población sin empleo ha hecho que se presente una situación de equilibrio entre población en edad laboral y población que trabaja. No obstante, los habitantes locales expresan una opinión desfavorable frente a la oferta y la calidad del empleo en el lugar. La falta de oferta, estabilidad y contratos laborales afectan la situación económica de Pueblo Viejo. Estas opiniones están acompañadas y parten de una añoranza por una época en la que hubo fuentes de empleo con buenas condiciones a nivel de estabilidad, oferta y prestaciones cuando funcionaba la compañía explotadora de cal. La principal actividad en esta región es la ganadería lechera, pues ofrece oportunidades de trabajo sin necesidad de invertir mucho dinero y es una respuesta a la falta de tierras cultivables.

La situación de empleo en Pueblo Viejo tiene relación con el ecoturismo como actividad propia del discurso neoliberal de la conservación ambiental. El neoliberalismo asigna valor económico a los ecosistemas, en este caso el bosque alto andino, que entra en circuitos de mercado, al ser conservado o restaurado por medio de bonos de carbono, o pago por servicios ambientales. Todo esto significa una extensión del 
mercado a nuevas esferas, en este caso la de la conservación ambiental. Son precisamente estas actividades del conservacionismo neoliberal las que generan trabajo en Pueblo Viejo, en particular para la atención de los visitantes que pagan por apreciar y restaurar los ecosistemas y la naturaleza. Esta forma neoliberal de producir el espacio de bosques como una actividad rentable sin necesidad de desmontar, sembrar o extraer directamente ningún mineral o elemento natural, sino dejando "intactos" los bosques, genera formas particulares de trabajo, que en el caso de Guasca no están empleando la mano de obra disponible o respondiendo a las expectativas de la gente.

Adicionalmente, este discurso neoliberal de la conservación ambiental de la mano del mercado interviene en la relación que los pobladores tienen con su entorno no solo en las prácticas, sino en su conceptualización. Nombres científicos y conceptos como el de biodiversidad entran en tensión con formas locales de comprender la naturaleza. Adicionalmente, el ecoturismo promueve nuevas maneras de explotación de los recursos naturales que entran en tensión con las actividades agropecuarias. En consecuencia, el ecoturismo es una de las caras de la política actual de administración de los recursos naturales bajo la lógica ambientalista que produce sujetos, naturaleza, espacios y nuevas labores.

En Guasca, el ecoturismo no ha respondido, como en muchos otros escenarios del mundo presentados en este capítulo, a las necesidades de subsistencia local. En este caso, la situación laboral es preciara, en especial para las mujeres, por lo que las personas ven en la FNC un lugar en el que, 
con algunos ajustes y nuevas propuestas en sus actividades, se pueden ofrecer puestos de trabajo para las personas del sector, en especial para las de género femenino, articuladas al ecoturismo. Sin embargo, muchas de estas propuestas no han sido trasmitidas a la FNC o acogidas por falta de canales de comunicación y debido a la desigualdad de poder de decisión entre las partes.

El empleo digno (de la mano del diálogo y la concertación) de pobladores locales en parques y reservas naturales constituye una opción de inclusión de la población local en el manejo de áreas protegidas que puede generar varias ventajas. Reduce la presión sobre los recursos naturales porque el brindar buenos empleos en labores asociadas a la conservación y las áreas protegidas representa una opción de ingresos sustentable, o por lo menos causante de inferiores daños al ambiente. En segundo lugar, puede llegar a fomentar la participación en su manejo, la escucha de sus opiniones y una alternativa de diálogo con las autoridades y administradores de las áreas protegidas. Finalmente, el círculo de pobreza y deterioro ambiental puede ser roto a partir de la generación de opciones de trabajo y la articulación de usos locales y usos de la conservación que serán objeto de análisis del siguiente capítulo.

Sin embargo, para el caso de la RBE, no se puede hablar de una articulación efectiva de la población en el manejo de la reserva, pues hacen falta espacios de diálogo, así como mejorar la calidad y cantidad de empleos en la RBE. Sin embargo, sigue siendo un problema, como se discutió en el capítulo i, que el derecho y las reglas de manejo sobre los recursos del entorno 
emanen no de la condición de habitantes de estas poblaciones, sino del otorgamiento que les es dado a estas personas por el estado o las organizaciones que hacen sus veces en el manejo ambiental (en este escenario, la FNC).

No deja de ser problemático que sean actores externos los que dictaminen las formas de uso de los recursos naturales y el manejo de áreas protegidas bajo el rol de jefes de la población local, como sucede en el caso del trabajo otorgado por áreas protegidas. En consecuencia, lo que se pone en discusión es la autonomía de gobierno y manejo de los recursos y territorios que ejercen las poblaciones locales a través del trabajo en áreas de conservación. 